\title{
Angiotensin II Angiogenic Effect In Vivo Involves Vascular Endothelial Growth Factor- and Inflammation-Related Pathways
}

\author{
Radia Tamarat, Jean-Sébastien Silvestre, Micheline Duriez, and Bernard I. Levy \\ INSERM U541, Hôpital Lariboisière, IFR Circulation-Paris 7, Université Paris 7-Denis Diderot, Paris, France
}

SUMMARY: Although accumulating lines of evidence indicate the proangiogenic role of angiotensin II (Ang II), little is known about the molecular mechanisms associated with such an effect. This study aimed to identify molecular events involved in Ang II-induced angiogenesis in the Matrigel model in mice. C57BI/6 female mice received a subcutaneous injection of either Matrigel or Matrigel with Ang II $\left(10^{-7} \mathrm{M}\right)$ alone, with Ang II and an AT1 receptor antagonist (candesartan, $\left.10^{-6} \mathrm{M}\right)$, or with Ang II and AT2 receptor antagonist (PD123319, 10 $\left.0^{-6} \mathrm{M}\right)$. After 14 days, angiogenesis was assessed in the Matrigel-plug by histological evaluation and cellular counting. Ang II increased by 1.9 -fold the number of cells within the Matrigel $(p<0.01$ versus control). Immunohistological analysis revealed the presence of macrophages, endothelial and smooth muscle cells, and the development of vascular-like structure. Such an angiogenic effect was associated with an increase in vascular endothelial growth factor (VEGF) (1.5-fold, $p<0.01$ ), endothelial nitric oxide (eNOS) (1.7-fold, $p<0.01$ ), and cyclooxygenase-2 (1.4-fold, $p<0.05)$ protein levels measured by Western blotting. Conversely, Ang II treatment did not affect MMP-9 and MMP-2 activity, assessed by zymography. Blockade of AT1 receptor completely prevented the Ang Il-induced angiogenesis and protein regulations, whereas that of AT2 was ineffective. Administration of VEGF neutralizing antibody $(2.5 \mu \mathrm{g}$ ip twice a week) and cyclooxygenase-2 selective inhibitor (nimesulide, $30 \mathrm{mg} / \mathrm{L}$ ) also hampered Ang II proangiogenic effect. In addition, Ang Il-induced cell ingrowth was impaired by treatment with nitric oxide synthase inhibitor (L-NAME, $10 \mathrm{mg} / \mathrm{kg} /$ day) and in eNOS-deficient mice. Therefore, in an in vivo model, Ang II induced angiogenesis through AT1 receptor, which involved activation of VEGF/eNOS-related pathway and of the inflammatory process. (Lab Invest 2002, 82:747-756).

$A$ ngiogenesis, the formation of new blood vessels from pre-existing ones, is involved in various physiological processes such as wound healing, corpus luteum formation, and embryonic development but also in many other pathological processes such as diabetic retinopathy and ischemic diseases.

Numerous factors modulated the angiogenic reaction. Among these factors, the renin-angiotensin system (RAS) might be involved in both beneficial angiogenesis and pathological vessel growth. Indeed, the biological active component of RAS, Angiotensin II (Ang II), stimulates endothelial and smooth muscle cells (SMC) proliferation in vitro (Stoll et al, 1995), increases vessel density in rat cremaster muscle (Munzenmaier and Greene, 1996) in the chorioallantoic membrane of the chick embryo (Le Noble et al, 1993), and activates in vivo angiogenesis in the rat subcutaneous sponge granuloma (Walsh et al, 1997). Ang II acts by at least two Ang II receptor subtypes, AT1 and AT2 (Chiu et al, 1989; Timmermans et al, 1993; Whitebread et al,

DOI: 10.1097/01.LAB.0000017372.76297.EB

Received January 14, 2002.

This work was supported by grants from INSERM, Université Paris 7. RT was supported by a grant from Société Française de Pharmacologie.

Address reprint requests to: Dr. Bernard I. Levy, U541-INSERM, Hôpital Lariboisière, 41 Bd de la Chapelle, 75475 Paris cedex 10, France. E-mail: levy@infobiogen.fr
1989). AT1 receptor has been shown to mediate growth stimulating function of Ang II, whereas AT2 seems to promote growth inhibition (Nakajima et al, 1995; Prescott et al, 1991; Stoll et al, 1995; Walsh et al, 1997). However, their detailed signal transduction mechanisms still remain controversial.

Ang II has several potential mechanisms that may increase the angiogenic process. First, Ang II may influence the angiogenic reaction by increasing vascular endothelial growth factor (VEGF) and basic fibroblast growth factor (bFGF) synthesis, two key growth factors implied in the angiogenic process (Cross and Claesson-Welsh, 2001). Hence, Ang II increases VEGF expression in endothelial cells and in an in vivo corneal assay (Fujiyama et al, 2001; Otani et al, 1998). The angiogenic response to VEGF might involve the production of nitric oxide (NO), as previously described in ischemia-induced angiogenesis (Murohara et al, 1998). VEGF increases the expression of both endothelial (eNOS) and inducible (iNOS) NO synthase and subsequently may affect the angiogenic process (Kroll and Waltenberge, 1998; Murohara et al, 1998). Similarly, Ang II, acting at AT1 receptor was found to increase bFGF synthesis in microvascular endothelial cells (Fischer et al, 1997). bFGF has been shown to modulate eNOS level and NO production leading to endothelial cell differentiation into vascular tubes (Babaei et al, 1998). Second, Ang II may modulate new vessel 
formation by regulating matrix metalloproteinases (MMP) production and activation. MMP are an important effector mechanism in angiogenesis (Stetler-Stevenson, 1999). Two members of the MMP endopeptidase family, MMP-9 (92 KD) and MMP-2 (72 KD), are able to degrade the extracellular matrix components of the basement membrane. Recently, Ang II has been shown to activate the MMP-9 gene transcription, which has been reported to affect the angiogenic process (Rouet-Benzineb et al, 2000; Vu et al, 1998). Third, Ang II exerts several direct effects relevant to the development of angiogenesis including stimulation of monocyte recruitment (Kim et al, 1996), activation of macrophages (Yanagitani et al, 1999), and enhanced cyclooxygenase-2 (COX-2) protein expression (Young et al, 1989). Activation of the inflammatory reaction and COX-2 has been found to regulate angiogenesis (Arras et al, 1997; Silvestre et al, 2000; Tsujii et al 1998) and might also be involved in Ang II angiogenic effect.

The aim of our study was, therefore, (1) to analyze the angiogenic effect of Ang II using the in vivo model of Matrigel in mice, (2) to identify molecular events involved in Ang II receptor activation by investigating changes in the VEGF/bFGF/NO pathway and MMP activity, and (3) to assess the role of the inflammatory reaction in Ang II proangiogenic effect.

\section{Results}

\section{Ang II-Induced Angiogenesis through AT1 Receptor Activation}

Histological score. The histological analysis showed that Ang II treatment increased cellular infiltration and proliferation in the plug (score 2) when compared with the control (score $1, p<0.01$ ). The addition of the AT1 receptor blocker candesartan abolished such effect (score 1, $p<0.05$ versus Ang II-treated Matrigel). On the contrary, the addition of the AT2 receptor blocker PD123319 did not significantly affect the Ang II angiogenic effect (score 3). Furthermore, in Ang II and AT2 receptor blocker treated Matrigel, the cells within the Matrigel formed numerous tube-like structures and the presence of erythrocytes was evidenced in the lumen demonstrating the existence of a functional vascular structure (Figs. 1, 2, and 3).

Endothelial cells marker. Histological scores were supported by CD31 immunostaining to specifically reveal endothelial cells. Ang II treatment increased by $60 \%$ the number of CD31 positive cells within the Matrigel. Such an effect was prevented by blockade of AT1 receptor but not by that of AT2 receptor (Figs. 2 and 3).

Cellular density. Histological data were confirmed by cellular density measurement. In Ang II-treated

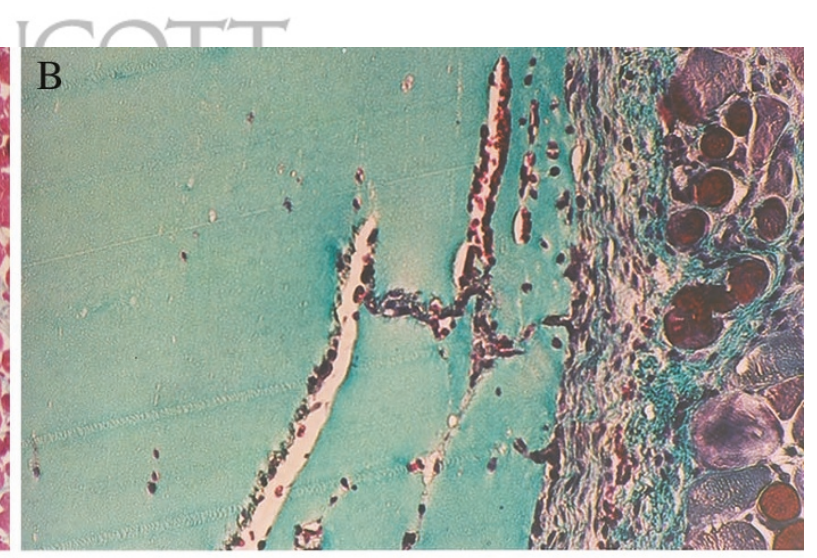

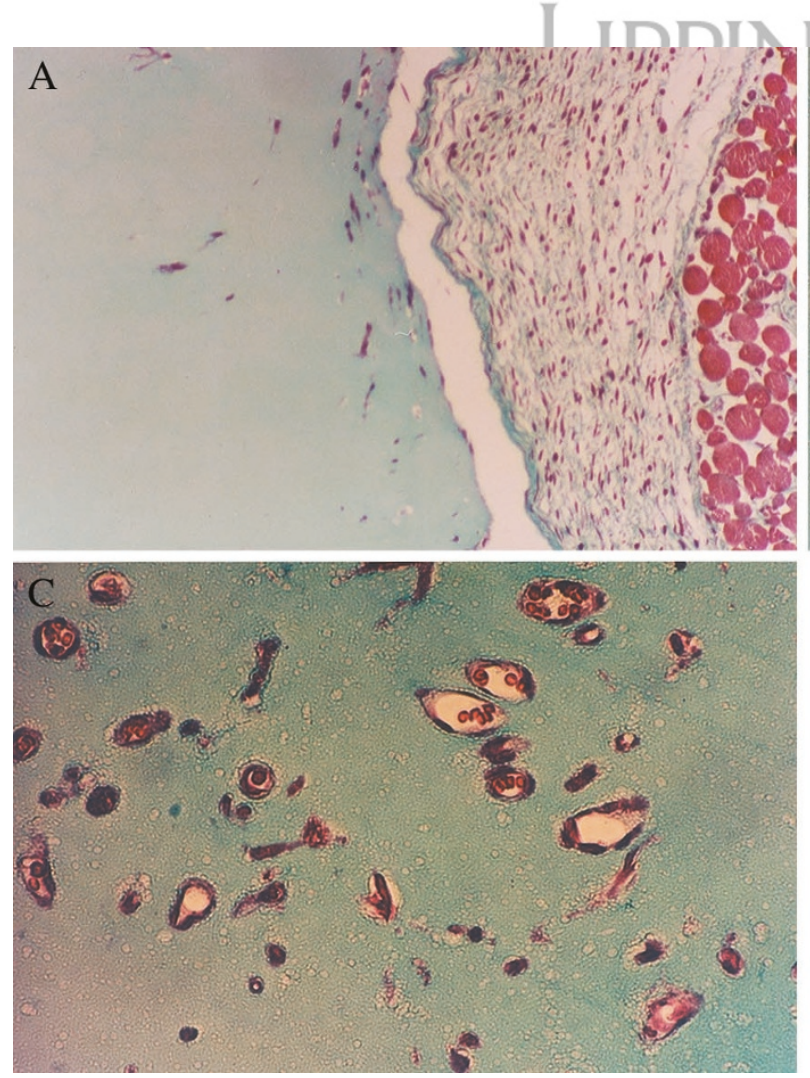

Figure 1.

Representative photomicrographs of Matrigel sections from control Matrigel (A), angiotensin II (Ang II)-treated Matrigel (B, C), stained with Masson Trichrome at a magnification of $\times 10(A, B)$ and $\times 40(C)$. A and B, Right: dermis and stromal interface; Left: Matrigel. 

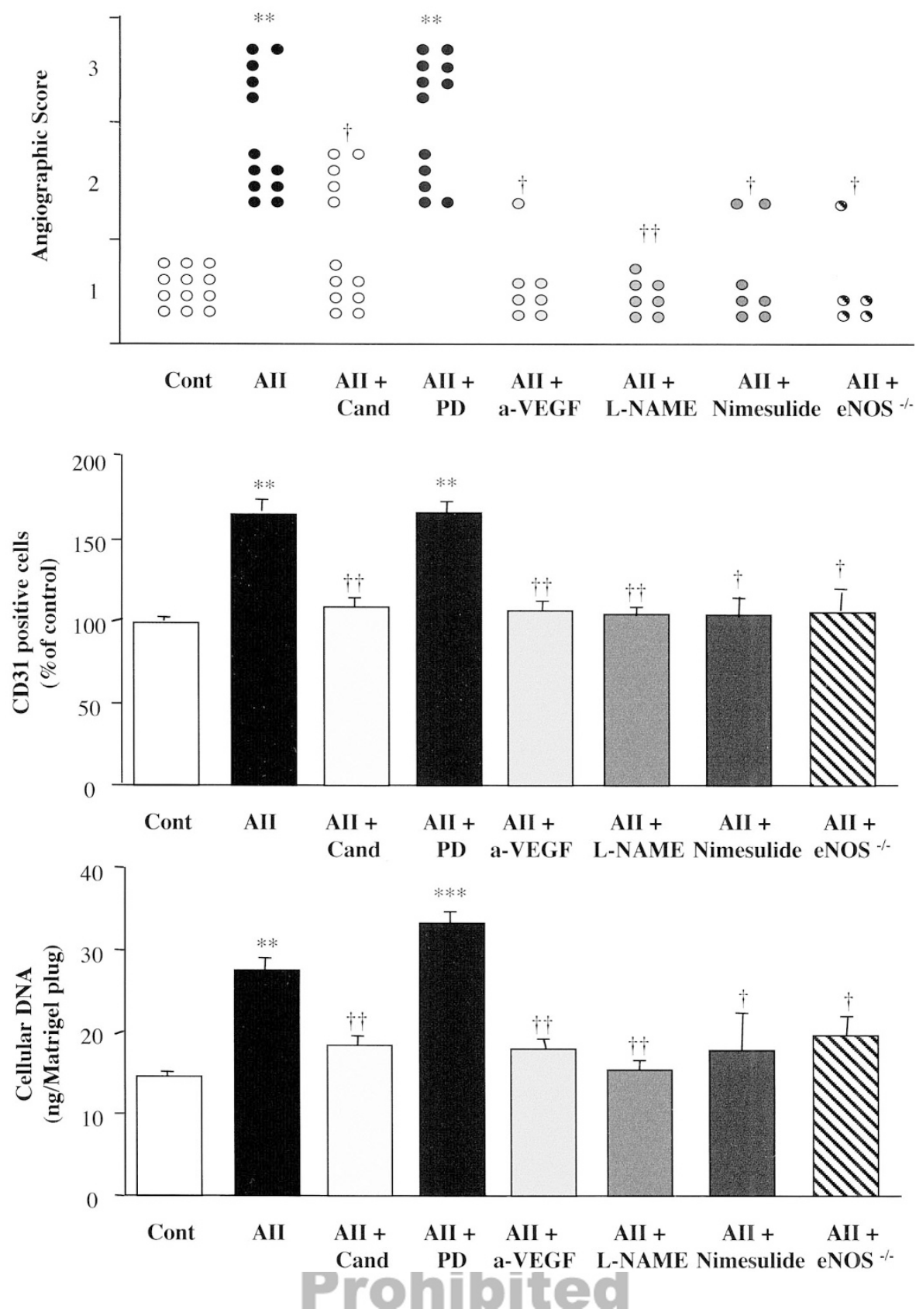

Figure 2.

Upper, semiquantitative analysis of Ang II angiogenic effect. Three different angiogenic scores were defined as follows: score 1, no colonization by cells or formation of a slight peripheric coat around the plug with a disorganized infiltration of cells; score 2, a cell coat thickened with a marked structural infiltration in the Matrigel; and score 3, a deep and massive infiltration of cells with erythrocyte presence. Middle, semiquantitative evaluation of CD31 positive cells. Values are mean \pm SEM, $n=7$ per group; $n=5$ par Ang Il-treated Matrigel in eNOS ${ }^{-/-}$mice. Lower, quantitative evaluation of cellular DNA. Values are mean \pm seM, $n=7$ per group; $n=$ 5 par Ang II-treated Matrigel in eNOS ${ }^{-/}$mice. ${ }^{* \star} p<0.01$ and ${ }^{* \star \star} p<0.001$ versus control Matrigel; $\dagger \dagger p<0.01$ versus Ang II-treated Matrigel. Cont, control Matrigel; All, Ang II-treated Matrigel; All+Cand, Ang II and candesartan-treated Matrigel; All+PD, Ang II and PD123319-treated Matrigel; All+a-VEGF, Ang II and neutralizing VEGF antibody-treated Matrigel; All+L-NAME, Ang II and NOS inhibitor-treated Matrigel; All+nimesulide, Ang II+COX-2 inhibitor treated Matrigel; All+eNOS ${ }^{--}$, Ang II-treated Matrigel in eNOS deficient mice.

Matrigel, cellular number was significantly higher by 1.9-fold when compared with that of the control $(p<$ 0.01). This increase in cellular density was prevented by candesartan treatment. In contrast, PD 123319 treatment did not significantly affect the Ang II-induced raise in cell number (Fig. 2).

Cell type determination in Matrigel plug. To determine the type of cells involved in Ang II-induced cell migration and proliferation into the Matrigel, specific staining was performed in the different treated groups. Analysis of serial sections stained with CD31 revealed that a majority of cells were endothelial cells in the Ang II-treated Matrigel. We also observed $\alpha$ actin smooth muscle staining indicating the presence of few smooth muscle cells (SMC) and the development of a mature defined vascular structure (Fig. 3). 
A)

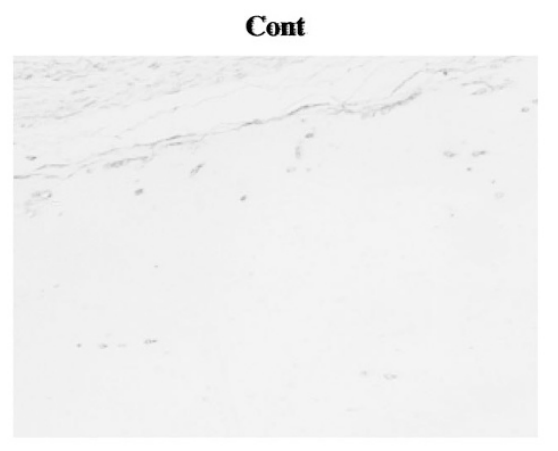

(x 20)

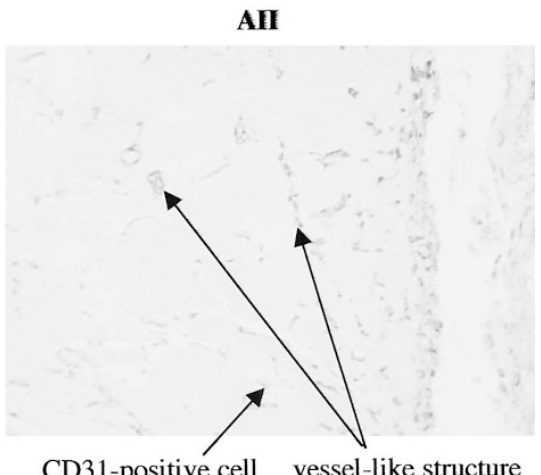

CD31-positive cell vessel-like structure

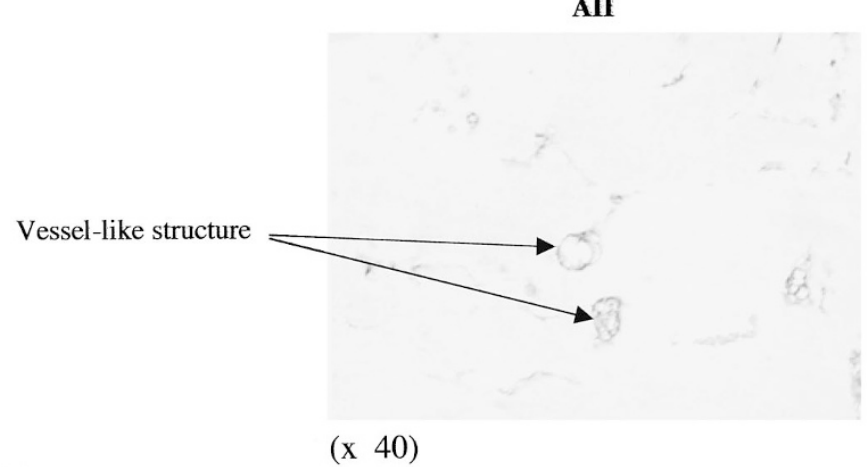

B)

AII

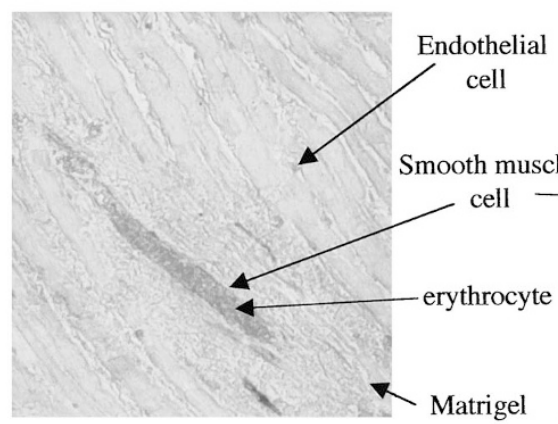

(x 10)
AII

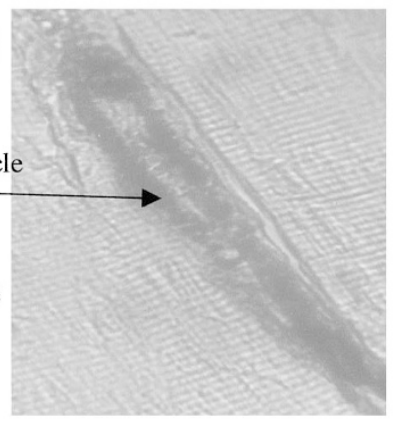

(x 40)

Figure 3.

A, Upper, representative photomicrographs of Matrigel sections from control Matrigel (Cont) and Ang II-treated Matrigel (All) hybridized with antibody directed against CD31 at a magnification of $\times 20$. Staining for CD31 appeared in brown. Lower, representative photomicrographs of Matrigel sections from Ang II-treated Matrigel (AII) at a magnification of $\times 40$. Staining for CD31 appeared in brown. B, Right, representative photomicrographs of Ang II-treated Matrigel hybridized with antibody directed against alpha smooth muscle cell (SMC) actin at a magnification of $\times 10$. SMCs appeared in red. Left, representative photomicrographs of Ang II-treated Matrigel hybridized with antibody directed against alpha SMC actin at a magnification of $\times 40$. All indicates Ang II-treated Matrigel.

\section{Ang II Angiogenic Effect Was Mediated by VEGF/eNOS Pathway}

VEGF. In animals injected with Matrigel+Ang II, VEGF level was increased by $144 \%$ when compared with untreated plug $(p<0.01)$. Interestingly, the AT1 receptor blockade prevented such an increase. Conversely, AT2 receptor blockade did not modulate Ang II-induced raise in VEGF level (Fig. 4A). The addition of VEGF neutralizing antibody completely abrogated Ang II-induced cell proliferation (Fig. 2), indicating that VEGF mediated Ang II proangiogenic effect. In an effort to localize VEGF, we performed immunohisto- chemistry by using anti-VEGF antibody. Ang IIcontaining Matrigel demonstrated a significant increase in immunodetectable VEGF primarily localized to cells within the neovascular stromal interface (Fig. $4 B$, left panel). We also detected VEGF immunostaining within the Matrigel, mainly localized into the endothelial cells (Fig. 4B, middle panel).

eNOS. Ang II angiogenic effect was also associated with variation in eNOS protein level. Hence, in animals injected with Matrigel+Ang II, eNOS content was higher by $174 \%$ when compared with that of untreated Matrigel $(p<0.01)$. This increase was prevented with 
A)

$\begin{array}{llll}\text { Cont } & \text { AII } \quad \begin{array}{c}\text { AII + } \\ \text { Cand }\end{array} & \begin{array}{c}\text { AII + } \\ \text { PD }\end{array} \\ \text { VEGF } & & & \end{array}$

B)

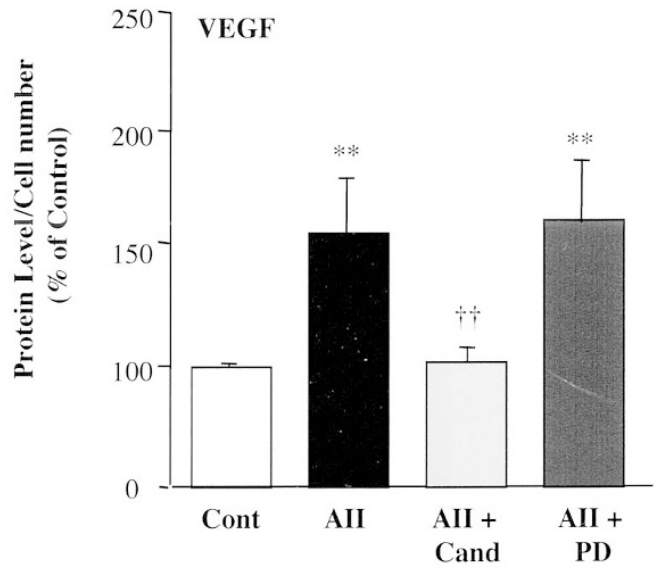

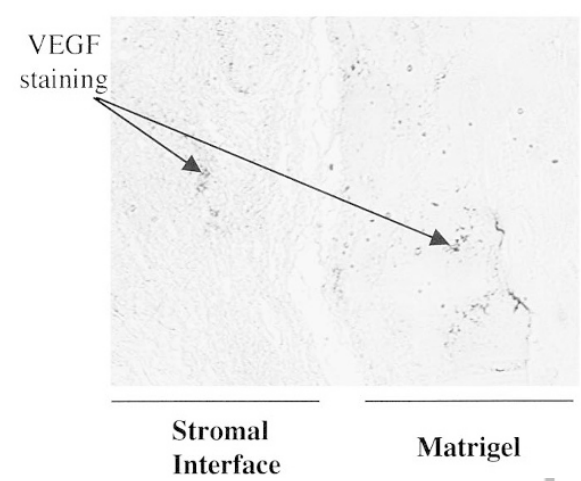

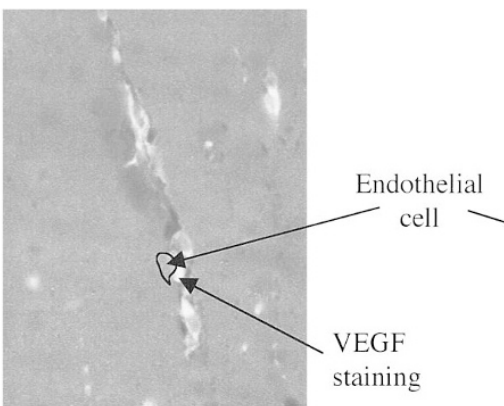

Matrigel

\section{Figure 4.}

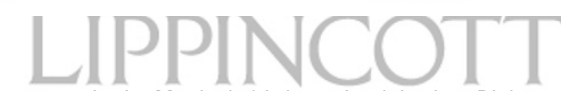

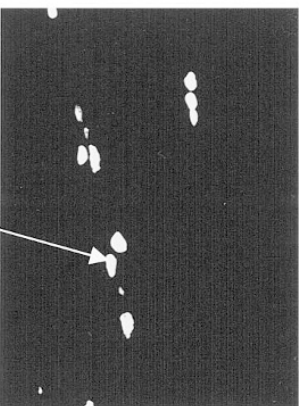

Matrigel (Cell nuclei)

A, Left, representative Western-blot of VEGF protein content in the Matrigel, 14 days after injection. Right, quantitative evaluation of VEGF protein levels expressed as a percentage of control Matrigel. Values are mean $\pm \operatorname{SEM}, n=7$ per group. ${ }^{* \star} p<0.01$ versus control Matrigel, $+\dagger p<0.01$ versus Ang II treated Matrigel. Same legend as Figure 2. B, Left panel, Ang II-treated Matrigel section stained with anti-VEGF antibody. The bound biotin-labeled antibodies were then detected by the addition of horseradish peroxidase-streptavidin conjugate and 3-amino-9-ethyl-carbazole (AEC) substrate. Staining for VEGF appeared in brown. Middle panel, Ang II-treated Matrigel section stained with anti-VEGF antibody and revealed with a fluorescent FITC anti-rabbit antibody. Staining for VEGF appeared in white. Right panel, counterstaining was performed by using 4',6-diamino-2-phenylindol to specifically reveal cell nuclei (white).

candesartan treatment. In contrast, PD123319 treatment tended to increase eNOS protein content by $80 \%$ when compared with Ang II treated Matrigel, but this enhancement did not reach statistical significance ( $p=0.07$ ) (Fig. 5). Interestingly, treatment with NOS inhibitor totally hampered Ang II-induced cell ingrowth (Fig. 2). Similarly, Ang II effect was impaired in eNOSdeficient (eNOS ${ }^{-/}$) mice, indicating that eNOS mediated Ang II proangiogenic effect (Fig. 2).

bFGF. No changes in bFGF protein level were observed in the control group (100 $\pm 17 \%)$, Ang II-treated Matrigel $(91 \pm 17 \%)$, Ang II+candesartantreated Matrigel (108 $\pm 11 \%)$, and Ang II+PD123319treated plug $(89 \pm 15 \%)$ (data not shown).

It is noteworthy that a slight level (at the threshold of detection) of VEGF and bFGF protein content was observed in the native noninjected Matrigel (data not shown).

MMP activity. The gelatin zymographic analysis revealed a major lytic band at $62 \mathrm{kDa}$ corresponding to the active form of MMP-2 and a minor lytic band of 72 $\mathrm{kDa}$ consistent with the proform of MMP-2. Gelatin zymographic analysis also revealed $92-$ and $82-\mathrm{kDa}$ gelatinolytic activities consistent with the pro and active forms of MMP-9, respectively. However, no significant changes in MMP-2 and MMP-9 activity were observed in either group (Fig. 6).

\section{Inflammatory Reaction Was Also Involved in Ang II-Induced Cell Ingrowth}

We showed the presence of macrophages within the Matrigel plug revealed by macrophage marker (MOMA)-2 staining (Fig. 7). Ang II treatment also increased COX-2 protein content by $42 \%$ over that of untreated matrigel $(p<0.05)$. Such an effect was blocked by AT1 receptor antagonist (Fig. 8). The key role of COX-2 was then emphasized by using COX-2 inhibitor. Ang II angiogenic effect was suppressed by COX-2 inhibitor treatment suggesting that COX-2 mediated Ang II-induced cell ingrowth (Fig. 2).

\section{Discussion}

This study shows that Ang II induced angiogenesis in the Matrigel model through AT1 receptor, which in- 
Cont AII AII + AII +

Cand PD

eNOS

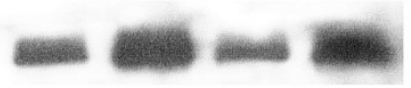

${ }^{300} 7$ eNOS

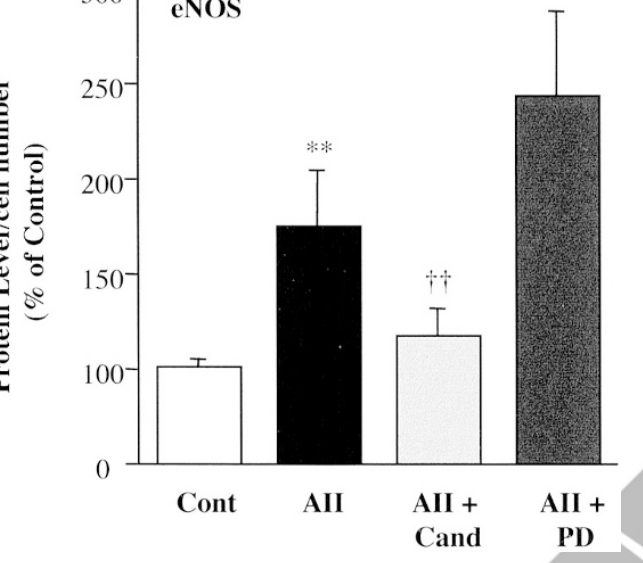

Figure 5.

Upper, representative Western-blot of endothelial nitric oxide (eNOS) protein content in the Matrigel, 14 days after injection. Lower, quantitative evaluation of eNOS protein levels expressed as a percentage of control Matrigel. Values are mean \pm SEM, $n=7$ per group. ${ }^{* \star} p<0.01$ and ${ }^{* \star *} p<0.001$ versus control Matrigel; $\dagger \dagger p<0.01$ versus Ang II-treated Matrigel. Same legend as Figure 2.

volved activation of the VEGF/eNOS-related pathway and of the inflammatory reaction.

In this study, we used the Mătrigel model as an in vivo angiogenesis assay. This model provides a useful tool in mice for investigating the effect of a variety of angiogenic and antiangiogenic factors, as previously reported (Claffey et al, 2001; Passaniti et al, 1997). As the Matrigel plug is initially avascular, vascular-like structures located within the Matrigel plug must be newly formed, reflecting then the angiogenic process.

We demonstrated that Ang II promoted the proliferation of endothelial cells and SMC in the Matrigel plug to form numerous tube-like structures in vivo. Presence of SMCs indicated the development of a mature defined vascular structure. Ang II-induced cell ingrowth was reduced by the AT1 receptor antagonist candesartan indicating that Ang II stimulates angiogenesis in the Matrigel model via AT1 receptor, as previously described (Munzenmaier and Greene, 1996; Stoll et al, 1995; Walsh et al, 1997). Conversely, Ang II angiogenic effect tends to be enhanced after AT2 receptor blockade. We can speculate that (1) the angiogenic process in the Matrigel model reaches a plateau phase or (2) the maximal response to the AT2 antagonist PD 123319 could be observed at another time point, ie, after 14 days of treatment. Nevertheless, this suggests that AT2 activation may be involved in antiangiogenic effect, as previously described (Munzenmaier and Greene, 1996; Nakajima et al, 1995; Walsh et al, 1997). However, no molecular mechanism
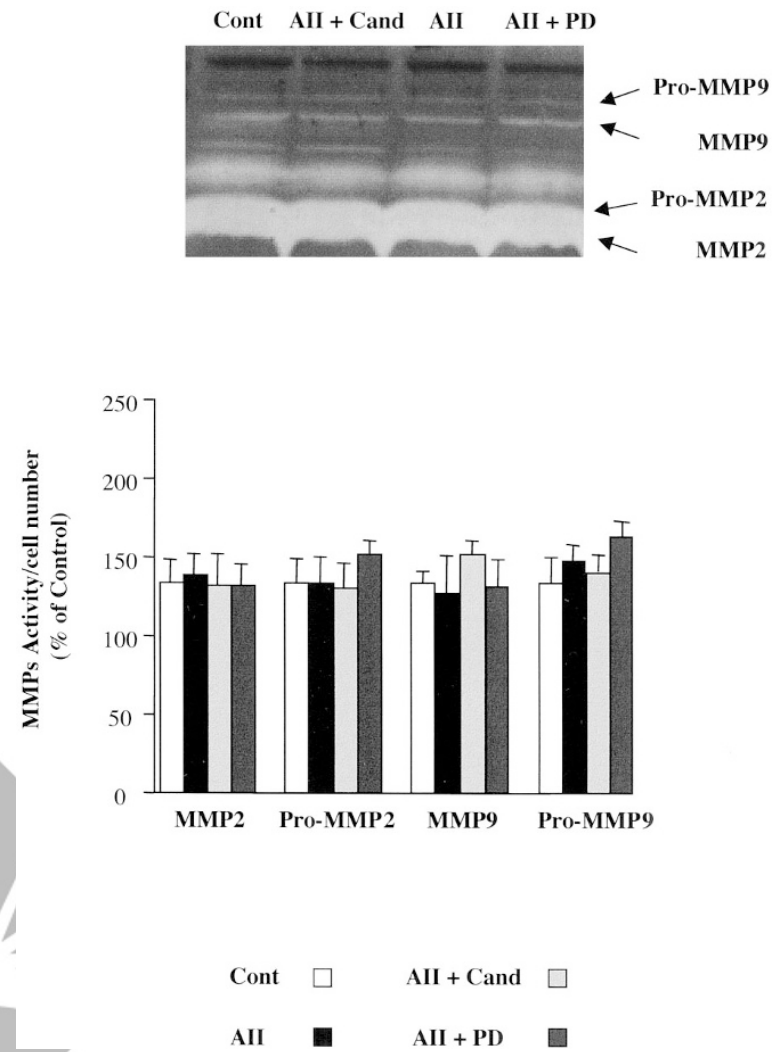

Figure 6.

Upper, representative gelatin zymographic analysis of protein extract from control Matrigel, Ang II-treated Matrigel alone and with candesartan or PD123319 treatment. Gelatin zymographic analysis revealed a lytic band at 62 $\mathrm{kDa}$ corresponding to the active form of metalloproteinases (MMP)-2, a minor Iytic band at $72 \mathrm{kDa}$ consistent with the proform of MMP-2, and two lytic bands at 92 and $82 \mathrm{kDa}$ consistent with the pro and the active form of MMP-9, respectively. For each group, $50 \mu \mathrm{g}$ of total proteins were used. Lower, densitometric analysis of zymographic gels. Values are mean \pm SEM, $n=7$ per group; $p<0.01$ and $p<0.001$ versus control Matrigel; $p<0.05$ and $p<$ 0.01 versus Ang II-treated Matrigel. Same legend as Figure 2.

has clearly been proposed in these previous studies. Thus, the cellular events involved in Ang II angiogenic response remains to be defined.

Ang II-induced angiogenesis was associated with a sustained increase in VEGF and eNOS levels. Both raises might result from the increase in cell number and subsequently might not mediate Ang II effect. To cope with changes in cell number, we expressed the results concerning protein content variations as a ratio of protein level to cell number. In addition, blockade of Ang II-induced cell ingrowth by administration of either VEGF neutralizing antibody or NOS inhibitor suggests that VEGF and eNOS mediated Ang II signaling. Ang II-induced cell ingrowth was also impaired in eNOS deficient mice emphasizing the key role of eNOS in such an effect. Both increases were prevented by AT1 receptor blockade demonstrating that AT1 receptor is involved in VEGF/eNOS pathway activation. Previous studies have shown that Ang II is a potent stimulus of VEGF-induced proliferation and tube formation in retinal microvascular endothelial cells through the induction of the VEGF receptor KDR/Flk-1 (Otani et al, 1998). Taken together, these 
Cont

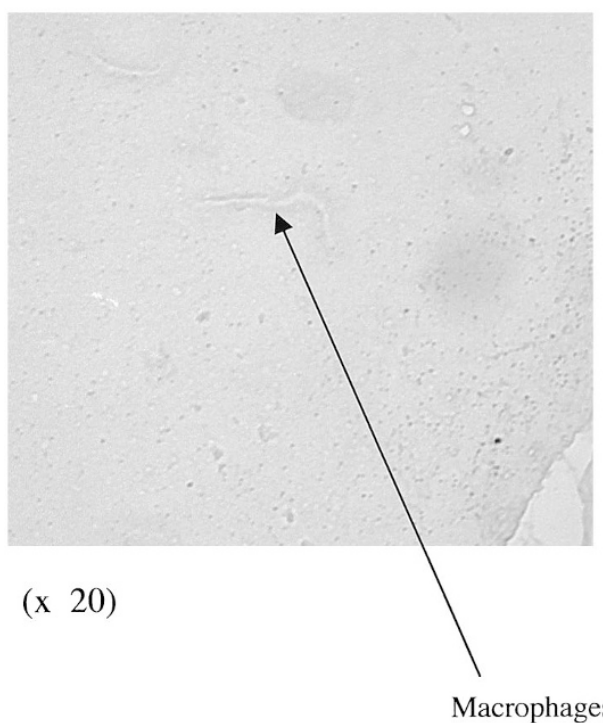

AII

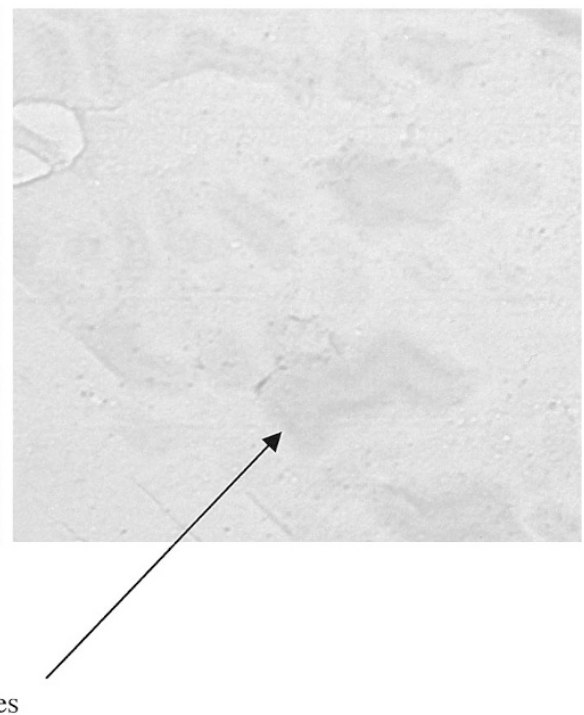

Figure 7.

Representative photomicrographs of control and Ang II-treated Matrigel hybridized with antibody directed against macrophage marker (MOMA)-2 at a magnification of $\times 40$. Macrophages appeared in red. Cont, control Matrigel; All, Ang II-treated Matrigel.

findings suggest that Ang II may act by stimulating VEGF synthesis but also by potentiating VEGF related effects. Our findings are also in agreement with previous in vivo and in vitro studies showing a strong correlation between angiogenesis, VEGF, and eNOS expression (Kroll and Waltenberge, 1998; Murohara et al, 1998). Involvement of NO in the proangiogenic effect of VEGF has already been described (Murohara et al, 1998; Ziche et al, 1997). We can then hypothesize a putative common pathway involving VEGF and $\mathrm{NO}$ in the Ang II-induced angiogenesis in vivo. We also observed immunolocalization of VEGF in stromal and endothelial cells of Ang II-treated Matrigel. Similarly, FGF-2 activated VEGF expression in stromal cell and subsequent cell ingrowth within the Matrigel (Claffey et al, 2001). FGF-2 and other angiogenic stimuli have also been shown to induce VEGF expression in endothelial cells of forming capillaries (Liu et al, 1995; Seghezzi et al, 1998). However, our data do not define whether the VEGF protein detected by immunohistochemistry is actually being expressed by stromal and endothelial cells or is derived from some other source such as SMC and macrophages which are present in the Ang II-treated Matrigel and which have been shown to produce VEGF (Cross and Claesson-Welsh, 2001; Sunderkotter et al, 1991).

In the present study, we also focused on the role of MMP activation as a putative molecular target in Ang II-induced angiogenesis. MMPs play an important role in angiogenesis, in part through matrix degradation and promotion of cell migration. Recent findings also suggest that MMP activity may directly influence cell behavior by stimulating the release of proangiogenic factors and by favoring the degradation of angiogenesis inhibitors (Stetler-Stevenson, 1999). However, in our experimental conditions, Ang II did not modulate MMP activity. It is likely that both Ang II and MMP pathways modulate distinct, but essential, cellular events involved in angiogenesis.

Inflammation is generally considered to represent the fundamental stimulus for angiogenesis. Monocytes/macrophages accumulation and cytokines production modulate vessel growth in ischemic tissues (Arras et al, 1997; Silvestre et al, 2000). In vivo lipolysaccharide administration increases capillary density as well as the number of macrophages in nonischemic tissues (Arras et al, 1997). Therefore, it is likely that recruitment and activation of resident macrophages are sufficient to activate the angiogenic process. Macrophage-derived peptide PR39 has been shown to increase VEGF expression and accelerates formation of vascular structures in vitro (Li et al, 2000). Ang II also promoted proliferation of macrophages in the Matrigel plug. The presence of these inflammatory cells might be associated with local secretion of several angiogenic factors, including cytokines, growth factors such as VEGF and bFGF, and MMPs (Arras et al, 1997; Silvestre et al, 2000; Sunderkotter et al, 1991). Ang II raised COX-2 protein content through AT1 receptor activation and Ang II angiogenic effect was suppressed by inhibition of COX-2, suggesting that COX-2 mediated Ang II-induced cell ingrowth. Taken together, these results underscore for the first time the major role of the inflammatory reaction in the modulation of Ang II-induced angiogenesis.

In conclusion, the present study confirms that Ang II exerts proangiogenic activity through its AT1 receptor. More importantly, our results underscore the critical role of VEGF and eNOS expression, independent of MMP activation, in promoting Ang II-induced cell ingrowth. This study also demonstrated for the first time the role of the inflammatory process in Ang II-induced angiogenesis. 


$\begin{array}{ccc}\text { Cont } & \text { AII } & \text { AII + } \\ \text { Cand } & \text { AII + } \\ & & \text { PD }\end{array}$

COX-2
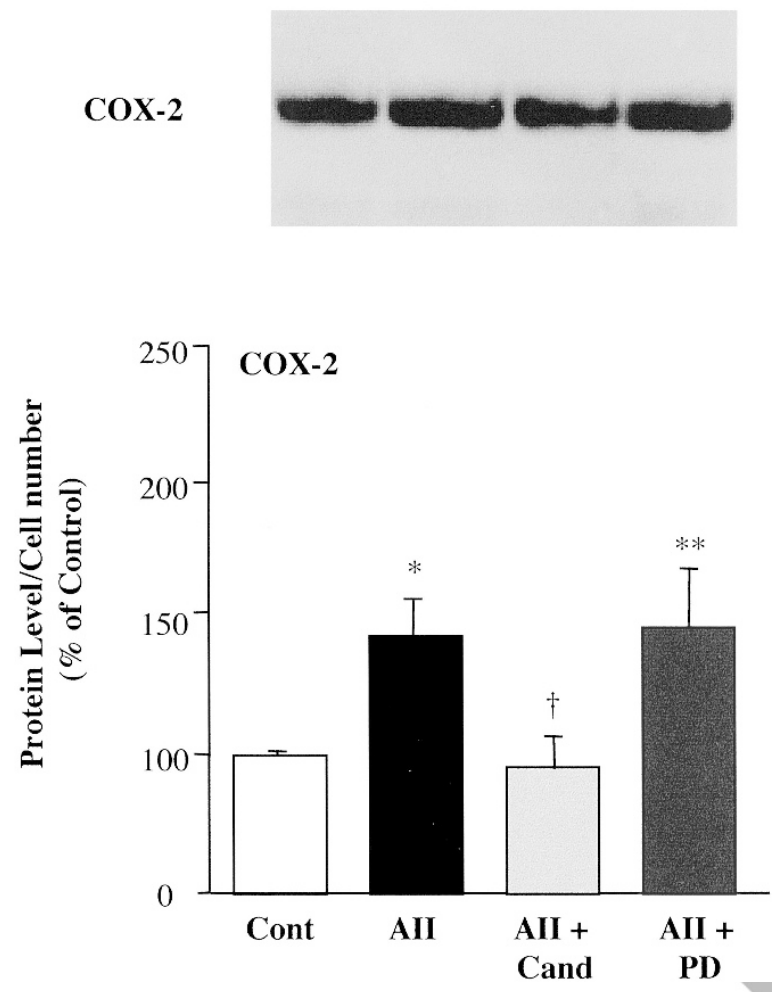

Figure 8.

Upper, representative Western-blot of cyclooxygenase-2 (COX-2) protein content in the Matrigel, 14 days after injection. Lower, quantitative evaluation of COX-2 protein levels expressed as a percentage of control Matrigel. Values are mean \pm SEM, $n=7$ per group. ${ }^{*} p<0.05$ and ${ }^{* *} p<0.01$ versus control Matrigel; $\dagger p<0.01$ versus Ang II-treated Matrigel. Same legend as Figure 2.

\section{Materials and Methods}

\section{In Vivo Angiogenesis Assay}

Sexually mature 8-week-old C57BI/6 female mice (IFFA-CREDDO, Lyon, France) received $0.5 \mathrm{ml}$ subcutaneous injection ( $n=12$ per groups) with either Matrigel alone (a basement membrane extract of the Engelbreth-Holm-Swarm mouse tumor) or Matrigel with Ang II $\left(10^{-7} \mathrm{M}\right)$, with Ang II $\left(10^{-7} \mathrm{M}\right)$ and candesartan (a specific AT1 receptor antagonist, $10^{-6} \mathrm{M}$; Astra, Hässle, Mölndal, Sweden), or with Ang II $\left(10^{-7}\right.$ M) and PD123319 (a specific AT2 receptor antagonist, $10^{-6} \mathrm{M}$; Sigma, St. Quentin Fallavier, France). The specific role of VEGF, eNOS, and COX-2 in Ang II-induced angiogenesis was assessed by treatment with an Ang II+VEGF neutralizing antibody $(2.5 \mu \mathrm{g}$ ip twice a week, $n=7$; R\&D Systems, Oxford, United Kingdom), Ang II+NO synthase inhibitor (L-NAME, 10 $\mathrm{mg} / \mathrm{kg} /$ day in the drinking water, $n=7$; Sigma), and Ang II+COX-2 inhibitor (nimesulide, $30 \mathrm{mg} / \mathrm{L}$ in the drinking water, $n=7$; Sigma). The key role of eNOS was then emphasized by using eNOS ${ }^{-1-}$ mice receiving Matrigel with Ang II ( $\left.10^{-7} \mathrm{M} ; n=5\right)$.

In a preliminary set of experiments, Ang $\| 10^{-7} \mathrm{M}$ was shown to induce a maximal angiogenic response (data not shown). After the injection, the Matrigel rapidly formed a subcutaneous plug that was left 14 days before prelevement.

\section{Matrigel Preparation}

On Day 14 , the mice were euthanized and the skin of the mice was easily pulled back to expose the Matrigel. Plugs were then removed and fixed with $3.7 \%$ formaldehyde at $4^{\circ} \mathrm{C}$ for 12 hours, embedded in paraffin, sectioned, and stained with Masson Trichrome (Reactifs RAL, Strasbourg, France). Successive sections $(5 \mu \mathrm{m})$ were then examined $(\times 40$ and $\times 4$ magnification, Olympus $\mathrm{BH}-2$; Leica, Paris, France).

\section{Quantification of Angiogenesis}

Histological score. The histological views were used for semiquantitative evaluation of angiogenesis. Three different scores were defined: score 1 , no colonization by cells or formation of a slight peripheric coat around the plug with a disorganized infiltration of cells; score 2, a cell coat thickened with a marked structural infiltration in the Matrigel; and score 3, a deep and massive infiltration with erythrocyte presence. Such scores were performed in a double-blind fashion.

Cellular density. The histological analysis was completed with a cellular density measurement using Cyquant Cell Proliferation Assay kit (Molecular Probes, Eugene, Oregon). The cells were isolated from fresh plugs by digestion with a collagenase cocktail (Becton Dickinson, Sunnyvale, California) at $4^{\circ} \mathrm{C}$ for 12 hours and centrifuged at $100 \times g$. Isolated cells were removed in buffer (PBS $+\mathrm{CaCl}_{2} 1 \mathrm{mM}+\mathrm{Mg} \mathrm{Cl}_{2}$ $1 \mathrm{~mm}$ ) and distributed on the 96 well plate. The plates were then incubated at $37^{\circ} \mathrm{C}$ to allow the cells to attach, centrifuged at $100 \times \mathrm{g}$, and frozen at $-80^{\circ} \mathrm{C}$ until the measure. The plates were thawed at room temperature, and $200 \mu \mathrm{l}$ of the CyQUANT GR dye/cell lysis buffer was added to each sample well (CyQUANT GR dye exhibits strong fluorescent enhancement when bound to cellular nucleic acids). Sample fluorescence was finally measured using a Fluoroscan device (Biolise, Paris, France) with filters appropriate for 480 $\mathrm{nm}$ excitation and $520 \mathrm{~nm}$ emission.

\section{Identification of the Cellular Types}

Five micrometer sections were prepared from paraffin-embedded Matrigel plugs. After deparaffinization and rehydratation in PBS, the sections were hybridized 45 minutes with antibody against monoclonal alpha smooth muscle actin to identify SMC (clone 1A4, dilution 1/50, M0851; DAKO, Bucks, United Kingdom). Adjacent sections were also hybridized $45 \mathrm{~min}-$ utes with antibody against CD31 to identify endothelial cells (dilution 1/20; Santa Cruz Biochemicals, Santa Cruz, California) and with antibody against MOMA-2 to identify macrophages (1/5, AMU0071; BioSource, Camarillo, California). The bound biotin-labeled antibodies were then detected by the addition of horseradish peroxidase-streptavidin conjugate and 3-amino-9-ethyl-carbazole (AEC) substrate. 


\section{Immunolocalization of VEGF}

Five micrometer sections were prepared from paraffin-embedded Matrigel plugs. After deparaffinization and rehydratation in PBS, the sections were hybridized 45 minutes with antibody against VEGF (1/50; Santa Cruz Biochemicals). The bound biotinlabeled antibodies were then detected by the addition of horseradish peroxidase-streptavidin conjugate and AEC substrate (Fig. 4B, left panel). VEGF immunolocalization within the Matrigel was also revealed with a fluorescent FITC anti-rabbit antibody (dilution 1/50; Fig. 4B, middle panel). Counterstaining was performed by using 4 ',6-diamino-2-phenylindol $(1 \mu \mathrm{g} / \mathrm{ml})$ to specifically reveal cell nuclei (Fig. 4B, right panel).

\section{Protein Preparation}

The plugs were thawed and homogenized in $1 \mathrm{ml}$ of ice-cold lysis buffer $(200 \mathrm{mmol} / \mathrm{L}$ sucrose, $20 \mathrm{mmol} / \mathrm{L}$ HEPES, pH 7.4) containing protease inhibitors. The homogenate was centrifuged at $10,000 \times g$ for 15 minutes in a Sorvall SS 34 rotor (Sorvall Instrument, Paris, France) at $4^{\circ} \mathrm{C}$ and the detergent-soluble supernatant fraction was retained. Protein content was then determined by the Bradford method (Bradford, 1976).

\section{Western Blot Analysis}

As previously described (Silvestre et al, 2000), proteins were separated in denaturing SDS $7.5 \%$ polyacrylamide gels and then blotted onto a nitrocellulose sheet (Hybond ECL; Amersham Pharmacia Biotech, Piscataway, New Jersey). Membranes were then incubated with antibody directed against either VEGF (1/2000; Santa Cruz Biochemicals), bFGF (1/1000; Santa Cruz Biochemicals), eNOS (1/5000; Santa Cruz Biochemicals), or COX-2 (1/1000; Santa Cruz Biochemicals).

\section{Zymography}

Protein samples were mixed in SDS-PAGE loading buffer (lacking reducing agents), applied to $9 \%$ SDSpolyacrylamide gel containing $1 \mathrm{mg} / \mathrm{mL}$ gelatin (BioRad, Hercules, California), and separated by electrophoresis. Subsequently, the SDS was removed from the gels by two washes (15 minutes) with $2.5 \%$ Triton $\mathrm{X}-100$, and the gels were incubated overnight at $37^{\circ} \mathrm{C}$ in zymography buffer $(50 \mathrm{mmol} / \mathrm{L}$ Tris, $\mathrm{pH} 7.5,10$ $\mathrm{mmol} / \mathrm{L} \mathrm{CaCl}_{2}$ ) and stained with Coomassie brilliant blue (Serva, Heidelberg, Germany). Gelatinolytic activity was visualized as clear areas of lysis in the gel. Densitometric analysis was performed using NIH Image software.

\section{Statistical Analysis}

Results are expressed as mean \pm SEM. For the control group, the average was calculated from the individual value and expressed as $100 \%$. The error bar evaluation was also calculated from the individual value and expressed as a percentage (with the average value that corresponds to $100 \%$ ). One-way analysis of variance was used to compare each parameter. Post hoc Bonferonni's $t$ test comparisons were then performed to identify which group differences account for the significant overall analysis of variance. A value of $p<$ 0.05 was considered significant. A $\chi^{2}$ test was also performed to analyze the difference observed in the score established for semiquantitative evaluation of angiogenesis (Fig. 2).

\section{References}

Arras M, Ito WD, Scholz D, Winkler B, Schaper J, and Schaper W (1997). Monocyte activation in angiogenesis and collateral growth in the rabbit hindlimb. J Clin Invest 101:4050.

Babaei S, Teichert-Kuliszewska K, Monge JC, Mohamed F, Bendeck MP, and Stewart DJ (1998). Role of nitric oxide in the angiogenic response in vitro to basic fibroblast growth factor. Circ Res 82:1007-1015.

Bradford M (1976). A rapid and sensitive method for the quantification of microgram quantities of protein utilizing the principle of protein-dye binding. Anal Biochem 72:248-254.

Chiu AT, Herblin WF, McCall DE, Ardecky RJ, Carini DJ, Duncia JV, Pease LJ, Wong PC, Wexler RR, and Johnson AL (1989). Identification of angiotensin II receptor subtypes. Biochem Biophys Res Commun 165:196-203.

Claffey KP, Abrams K, Shih SC, Brown LF, Mullan A, and Keough M (2001). Fibroblast growth factor activation of stromal cell vascular endothelial growth factor expression and angiogenesis. Lab Invest 81:61-75.

Cross MJ and Claesson-Welsh L (2001). FGF and VEGF function in angiogenesis: Signalling pathways, biological responses and therapeutic inhibition. Trends Pharmacol Sci 22:201-207.

Fischer TA, Ungureanu-Longrois D, Singh K, de Zengotita J, DeUgarte D, Alali A, Gadbut AP, Lee MA, Balligand JL, Kifor I, Smith TW, and Kelly RA (1997). Regulation of bFGF expression and ANG II secretion in cardiac myocytes and microvascular endothelial cells. Am J Physiol 272(2 Pt 2): H958-968.

Fujiyama S, Matsubara H, Nozawa Y, Maruyama K, Mori Y, Tsutsumi $Y$, Masaki H, Uchiyama $Y$, Koyama $Y$, Nose A, Iba O, Tateishi E, Ogata N, Jyo N, Higashiyama S, and Iwasaka $\mathrm{T}$ (2001). Angiotensin AT(1) and AT(2) receptors differentially regulate angiopoietin-2 and vascular endothelial growth factor expression and angiogenesis by modulating heparin binding-epidermal growth factor (EGF)-mediated EGF receptor transactivation. Circ Res 88:22-29.

Kim JA, Berliner JA, and Nadler JL (1996). Angiotensin II increases monocyte binding to endothelial cells. Biochem Biophys Res Commun 226:862-868.

Kroll $\mathrm{J}$ and Waltenberge $\mathrm{J}$ (1998). VEGF-A induces expression of eNOS and iNOS in endothelial cells via VEGF receptor-2 (KDR). Biochem Biophys Res Commun 252:743746.

Le Noble FA, Schreurs NH, van Straaten HW, Slaaf DW, Smits JF, Rogg H, and Struijker-Boudier HA (1993). Evidence for a novel angiotensin II receptor involved in angiogenesis in chick embryo chorioallantoic membrane. Am J Physiol 264(2 Pt 2):R460-465. 
Li J, Post M, Volk R, Gao Y, Li M, Metais C, Sato K, Tsai J, Aird W, Rosenberg R, Hampton TG, Li J, Sellke F, Carmeliet $P$, and Simons M (2000). PR39, a peptide regulator of angiogenesis. Nat Med 6:49-55.

Liu Y, Cox SR, Morita T, and Kourembanas S (1995). Hypoxia regulates vascular endothelial growth factor gene expression in endothelial cells. Identification of a 5 'enhancer. Circ Res $77: 638-643$.

Munzenmaier DH and Greene AS (1996). Opposing actions of angiotensin II on microvascular growth and arterial blood pressure. Hypertension 27(3 Pt 2):760-765.

Murohara T, Takayuki A, Silver M, Bauters C, Masuda $H$, Kalka C, Kearney M, Chen D, Chen D, Symes JF, Fishman MC, Huang PL, and Isner JM (1998). Nitric oxide synthase modulates angiogenesis in response to tissue ischemia. J Clin Invest 101:2567-2578.

Nakajima M, Hutchinson HG, Fujinaga M, Hayashida W, Morishita R, Zhang L, Horiuchi M, Pratt RE, and Dzau VJ (1995). The angiotensin II type 2 (AT2) receptor antagonizes the growth effects of the AT1 receptor: Gain-of-function study using gene transfer. Proc Natl Acad Sci USA 92: 10663-10667.

Otani A, Takagi H, Suzuma K, and Honda Y (1998). Angiotensin II potentiates vascular endothelial growth factorinduced angiogenic activity in retinal microcapillary endothelial cells. Circ Res 82:619-628.

Passaniti A, Taylor RM, Pili R, Guo Y, Long PV, Haney JA, Pauly RR, Grant DS, and Martin GR (1997). A simple, quantitative method for assessing angiogenesis and antiangiogenic agents using reconstituted basement membrane, heparin, and fibroblast growth factor. Lab Invest 67:519-528.

Prescott MF, Webb RL, and Reidy MA (1991). Angiotensinconverting enzyme inhibitor versus angiotensin II, AT1 receptor antagonist: Effects on smooth muscle cell migration and proliferation after balloon catheter injury. Am J Pathol 139: 1291-1296.

Rouet-Benzineb P, Gontero B, Dreyfus P, and Lafuma C (2000). Angiotensin II induces nuclear factor-kappa B activation in cultured neonatal rat cardiomyocytes through protein kinase $C$ signaling pathway. Mol Cell Cardiol 32:1767-1778.

Seghezzi G, Patel S, Ren CJ, Gualandris A, Pintucci G, Robbins ES, Shapiro RL, Galloway AC, Rifkin DB, and Mignatti P (1998). Fibroblast growth factor-2 (FGF-2) induces vascular endothelial growth factor (VEGF) expression in endothelial cells of forming capillaries: An autocrine mechanism contributing to angiogenesis. J Cell Biol 141:1659-1673.

Silvestre JS, Mallat Z, Duriez M, Tamarat R, Bureau MF, Scherman D, Duverger N, Branellec D, Tedgui A, and Levy BI (2000). Antiangiogenic effect of interleukin-10 in ischemiainduced angiogenesis in mice hindlimb. Circ Res 87:448452.
Stetler-Stevenson WG (1999). Matrix metalloproteinases in angiogenesis: A moving target for therapeutic intervention. $\mathrm{J}$ Clin Invest 103:1237-1241.

Stoll M, Steckelings UM, Paul M, Bottari SP, Metzger R, and Unger T (1995). The angiotensin AT2-receptor mediates inhibition of cell proliferation in coronary endothelial cells. J Clin Invest 95:651-657.

Sunderkotter C, Goebeler M, Schulze-Osthoff K, Bhardwaj R, and Sorg C (1991). Macrophage-derived angiogenesis factor. Pharm Ther 51:195-216.

Timmermans PB, Wong PC, Chiu AT, Herblin WF, Benfield P, Carini DJ, Lee RJ, Wexler RR, Saye JA, and Smith RD (1993). Angiotensin II receptors and angiotensin II receptor antagonists. Pharmacol Rev 45:205-251.

Tsujii M, Kawano S, Tsuji S, Sawaoka H, Hori M, and Dubois RN (1998). Cyclooxygenase regulates angiogenesis induced by colon cancer cells. Cell 93:705-716.

Vu TH, Shipley JM, Bergers G, Berger JE, Helms JA, Hanahan D, Shapiro SD, Senior RM, and Werb Z (1998). MMP-9/ gelatinase $B$ is a key regulator of growth plate angiogenesis and apoptosis of hypertrophic chondrocytes. Cell 93:411422.

Walsh DA, Hu DE, Wharton J, Catravas JD, Blake DR, and Fan TP (1997). Sequential development of angiotensin receptors and angiotensin I converting enzyme during angiogenesis in the rat subcutaneous sponge granuloma. Br J Pharmacol 120:1302-1311.

Whitebread S, Mele M, Kamber B, and De-Gasparo M (1989). Preliminimary bio-chemical characterization of two angiotensin II receptor subtypes. Biochem Biophys Res Commun 163:284-291.

Yanagitani Y, Rakugin H, Okamura A, Moriguchi K, Takiuchi S, Ohishi M, Suzuki K, Higaki J, and Ogihara T (1999). Angiotensin II type 1 receptor-mediated peroxyde production in human macrophages. Hypertension 33:335-339.

Young W, Mahboubi K, Haider A, Li I, and Ferreri NR (1989). Cyclooxygenase-2 is required for tumor necrosis factor $\alpha$ and angiotensin II-mediated proliferation of vascular smooth muscle cells. Circ Res 86:906-914.

Ziche M, Morbidelli L, Choudhuri R, Zhang HT, Donnini S, Granger HJ, and Bicknell R (1997). Nitric oxide synthase lies downstream from vascular endothelial growth factor-induced but not basic fibroblast growth factor-induced angiogenesis. J Clin Invest 99:2625-2634. 